\title{
Visual and Refractive Outcomes after Cataract Surgery with Implantation of a New Toric Intraocular Lens
}

\author{
Cinzia Mazzini \\ Clinica Oculistica, Azienda Ospedaliero-Universitaria Careggi, Florence, Italy
}

\section{Key Words}

Tecnis ZCT · Aspheric toric intraocular lens · Cataract surgery $\cdot$ Higher-order aberrations

\begin{abstract}
Purpose: The aim of this study was to evaluate and report the visual, refractive and aberrometric outcomes of cataract surgery with implantation of the new aspheric Tecnis ZCT toric intraocular lens (IOL) in eyes with low to moderate corneal astigmatism. Methods: We conducted a prospective study of 19 consecutive eyes of 17 patients (mean age: 78 years) with a visually significant cataract and moderate corneal astigmatism [higher than 1 diopter (D)] undergoing cataract surgery with implantation of the aspheric Tecnis ZCT toric IOL (Abbott Medical Optics). Visual, refractive and aberrometric changes were evaluated during a 6-month follow-up. Ocular aberrations as well as IOL rotation were evaluated by means of the OPD-Station II (Nidek). Results: The six-month postoperative spherical equivalent and power vector components of the refractive cylinder were within $\pm 0.50 \mathrm{D}$ in all eyes (100\%). Postoperative logMAR uncorrected and corrected distance visual acuities (UDVA/CDVA) were 0.1 (about 20/25) or better in almost all eyes (94.74\%). The mean logMAR CDVA improved significantly from $0.41 \pm 0.23$ to $0.02 \pm 0.05$ ( $p<0.01$ ). No significant changes were found in corneal astigmatism $(p=0.73)$. The mean IOL rotation was $3.33 \pm 1.94^{\circ}$. This parameter did not correlate with higher-order aberrations $(r=-0.09, p=0.73)$. A significant improvement in the Strehl ratio was also observed $(p<0.01)$, which was consistent with the significant reduction in higher-order aberrations $(p=0.02)$. Conclusion: Cataract surgery with implantation of the aspheric Tecnis ZCT IOL is a predictable and effective procedure for visual rehabilitation in eyes with cataract and low to moderate corneal astigmatism, providing an excellent postoperative ocular optical quality.
\end{abstract}




\section{Introduction}

Different types of intraocular lens (IOL) designs have been developed, some of them attempting to provide a restoration not only of the distance visual function, but also of the intermediate and near vision [1-4]. One of the most recent challenges has been the correction of a preexisting astigmatism induced by corneal toricity by means of an optimized IOL that provides an excellent postoperative visual acuity. This has been achieved with the development and introduction of toric IOLs in clinical practice, which have been shown to provide an enhanced visual and refractive effect over opposite clear corneal incisions [5]. Several authors have confirmed the efficacy, safety and predictability of the refractive correction with the different available models of toric IOLs [5-10]. The aim of the current study was to evaluate the visual, refractive and aberrometric outcomes of cataract surgery with implantation of a new aspheric toric IOL, the Tecnis ZCT, in eyes with a low to moderate corneal astigmatism.

\section{Methods}

\section{Patients}

In this prospective consecutive study, 19 cataractous eyes of 17 patients with ages ranging between 69 and 88 years were included. The inclusion criteria of this study were a patient age of 45 years or older, the presence of a visually significant cataract and corneal astigmatisms of more than 1 diopter (D). Exclusion criteria were a history of glaucoma or retinal detachment, active ocular disease or previous intraocular surgery. All volunteers were adequately informed and signed a consent form. The study adhered to the tenets of the Declaration of Helsinki and was approved by the local Ethics Committee.

\section{Examination Protocol}

Preoperatively, all patients had a full ophthalmologic examination, including the evaluation of the refractive status, $\log M A R$ uncorrected and corrected distance visual acuity (UDVA/CDVA) testing, slit lamp examination, Goldmann applanation tonometry and funduscopy. Besides these basic clinical tests, other specific examinations, such as corneal topography and ocular aberrometry (OPD-Scan II system; Nidek), biometry (IOL-Master v.3.01; Carl Zeiss Meditec) and endothelial cell count (Konan Cell Check CC-7000; CSO), were performed. The following parameters from the aberrometric analysis were compared and recorded: (1) the ratio of total aberrations in an emmetropic eye of reference and that corresponding to the measured eye (A/B); (2) the ratio of higher-order aberrations in an emmetropic eye of reference and that corresponding to the measured eye (H/B), and (3) the Strehl ratio, which is defined as the ratio of peak focal intensities in the aberrated and ideal point spread function.

Postoperatively, patients were evaluated during the follow-up at 1 day, 1 month, 3 months and 6 months after surgery. At 1 day after surgery, only UDVA, IOP and the integrity of the anterior segment were evaluated. The postoperative examination protocol at 1,3 and 6 months was identical to the preoperative protocol, with the additional analysis of the rotation of the IOL on the slit-lamp examination by checking the position of the indentations locating the flat meridian of the optic and comparing it with the target. 
Mazzini: Visual and Refractive Outcomes after Cataract Surgery with Implantation of a New Toric Intraocular Lens

\section{Surgery}

All surgeries were performed by the same experienced surgeon (C.M.) using a standard mini-incision sutureless microcoaxial phacoemulsification technique. In all cases, a corneal incision of $2.2 \mathrm{~mm}$ at $90^{\circ}$ was planned. The 0 -degree and 180-degree positions were marked on the slit lamp with a sterile Buratto marker after the patient's head was vertically aligned to control and prevent cyclorotations during surgery. After capsulorhexis creation and phacoemulsification, the IOL was inserted into the capsular bag using the Platinum injector (Abbott Medical Optics). The same postoperative treatment was administered to all patients, consisting of corticosteroid-antibiotic combination eye drops.

\section{Statistical Analysis}

SPSS statistics software package version 19.0 for Windows (IBM, Armonk, N.Y., USA) was used for statistical analysis. Normality of all data samples was first evaluated by means of the Kolmogorov-Smirnov test. When a parametric analysis was possible, the Student $t$ test for paired data was performed for all parameter comparisons between preoperative and postoperative examinations or consecutive postoperative visits. On the contrary, when parametric analysis was not possible, the Wilcoxon rank sum test was applied, using the same level of significance $(p<0.05)$ in all cases. Correlation coefficients (Pearson or Spearman, depending if normality condition could be assumed) were used to assess the correlation between different variables. The spherocylindrical refractions obtained before and after surgery were converted to vector notation using the power vector method described by Thibos and Horner [11].

\section{Results}

A total of 19 eyes of 17 patients with a mean age of 78 years [Standard deviation (SD): 5.6; range: 69-88] were included. Six patients were male (35.29\%) and 11 were female (64.71\%). The mean axial length was $23.08 \mathrm{~mm}$ (SD: 0.98; range: 21.46-25.45), the mean IOL spherical power implanted was 22.05 D (SD: 2.99; range: 16.5-27) and the mean IOL cylindrical power was $2.33 \mathrm{D}$ (SD: 0.61; range: $1.50-3.00$ ).

\section{Visual and Refractive Outcomes}

Table 1 summarizes the visual and refractive outcomes. As shown, a significant change in the visual acuity and manifest refractive cylinder (cyl) was found. logMAR UDVA was 0.1 or better in almost all cases (18 eyes, 94.74\%) at 6 months after surgery. logMAR CDVA improved significantly after surgery $(\mathrm{p}<0.01)$, with a 6 -month postoperative logMAR CDVA of 0.1 or better in almost all cases (18 eyes, 94.74\%). The spherical equivalent (M) was not modified significantly with surgery $(\mathrm{p}=0.80$ and $\mathrm{p}=0.15$, respectively), whereas the magnitude of the cyl was significantly reduced at 6 months after surgery $(p<0.01)$ (fig. 1). However, no significant reduction in the astigmatic power vector components $\mathrm{J}_{0}(\mathrm{p}=0.16)$ and $J_{45}(p=0.85$ ) was observed (fig. 2). At 6 months after surgery, $100 \%$ of the eyes had an $\mathrm{M}, \mathrm{J}_{0}$, and $\mathrm{J}_{45}$ within $\pm 0.50 \mathrm{D}$.

\section{Keratometric Changes}

No statistically significant changes with surgery were observed in the flattest and steepest keratometric readings ( $p=0.52$ and 0.77 , respectively) (table 1). The magnitude of corneal astigmatism remained stable after surgery $(\mathrm{p}=0.73)$, with mean preoperative and postoperative values of $1.66 \mathrm{D}$ (SD: 0.49; range: 1.10-2.90) and 1.64 D (SD: 0.42; range: 
Mazzini: Visual and Refractive Outcomes after Cataract Surgery with Implantation of a New Toric Intraocular Lens

1.00-2.60), respectively. No significant correlation was found between the preoperative magnitude of corneal astigmatism and the postoperative magnitude of the cyl $(\mathrm{r}=0.12, \mathrm{p}=$ 0.61). Likewise, the postoperative astigmatic power vector components did not correlate significantly with the magnitude of the preoperative corneal cylinder $\left(\mathrm{J}_{0}, \mathrm{r}=0.07, \mathrm{p}=0.78\right.$; $\left.\mathrm{J}_{45}, \mathrm{r}=-0.23, \mathrm{p}=0.34\right)$. No significant correlations of corneal astigmatic variation with changes in the magnitude of the cyl $(r=-0.21, p=0.38), J_{0}(r=0.21, p=0.39)$ and $J_{45}(r=$ $0.13, p=0.59$ ) were found.

\section{Ocular Aberrometric Changes}

A significant increase in the aberrometric parameters $\mathrm{A} / \mathrm{B}$ and $\mathrm{H} / \mathrm{B}(\mathrm{p}<0.01$ and $\mathrm{p}=$ 0.02 , respectively) was found after surgery (table 2). This increase in $A / B$ and $H / B$ represents an aberrometric reduction because these parameters are coefficients obtained by comparing the ratio of aberrations in an emmetropic eye of reference to that existing in each analyzed eye of the current sample. In concordance with this aberrometric reduction, an increase in the Strehl ratio was observed postoperatively $(p<0.01)$. No significant correlations of the postoperative logMAR CDVA with the aberrometric parameters $(\mathrm{A} / \mathrm{B}, \mathrm{r}=-0.39$ $\mathrm{p}=0.10 ; \mathrm{H} / \mathrm{B}, \mathrm{r}=-0.16, \mathrm{p}=0.52$; Strehl ratio, $\mathrm{r}=-0.37, \mathrm{p}=0.12$ ) were found.

\section{IOL Rotation}

The mean IOL rotation was $-1.78^{\circ}$ (SD: 3.49 ; range: -7 to 4 ) with a mean absolute value of $3.33^{\circ}$ (SD: 1.94; range: $1-7$ ). No significant correlations were found between IOL rotation and the magnitude of the postoperative cyl (postoperative rotation cyl, $r=0.11, p=0.66$; absolute postoperative rotation cyl, $r=0.11, \mathrm{p}=0.68$ ). Likewise, the postoperative astigmatic power vector components did not correlate significantly with IOL rotation (postoperative rotation $\mathrm{J}_{0}, \mathrm{r}=0.13, \mathrm{p}=0.61$; absolute postoperative rotation $\mathrm{J}_{0}, \mathrm{r}=-0.12, \mathrm{p}=$ 0.64; postoperative rotation $\mathrm{J}_{45}, \mathrm{r}=-0.31, \mathrm{p}=0.21$; absolute postoperative rotation $\mathrm{J}_{45}, \mathrm{r}=$ $-0.40, p=0.09$ ). Furthermore, IOL rotation did not correlate significantly with the postoperative level of higher-order aberrations (postoperative rotation $\mathrm{H} / \mathrm{B}, \mathrm{r}=0.33, \mathrm{p}=0.19$; absolute postoperative rotation $\mathrm{H} / \mathrm{B}, \mathrm{r}=-0.09, \mathrm{p}=0.73$ ).

\section{Discussion}

The mean postoperative logMAR UDVA was $0.02(\sim 20 / 20)$ in the analyzed sample, ranging from $0.00(20 / 20)$ to $0.22(\sim 20 / 30)$. This outcome confirms that this aspheric toric IOL provides a predictable correction of the spherocylindrical error in cases of low to moderate corneal astigmatism. Indeed, $100 \%$ of the eyes analyzed had a spherical equivalent within $\pm 0.50 \mathrm{D}$ of emmetropia at 6 months after surgery. Likewise, the postoperative power vector components were also within $\pm 0.50 \mathrm{D}$ in the analyzed sample. As expected, a significant reduction in the absolute magnitude of the cyl was found, but no significant changes in the astigmatic power vector components were detected. This last finding may be explained by the small sample size and the large variability in the values of these components due to the preoperative variability in the axis cylinder. Table 3 shows a comparative overview of the visual and refractive outcomes reported in other series evaluating different models of toric IOLs. It is being noted that the comparisons presented in this table should be made with care because different samples of eyes with different levels of astigmatism were evaluated, and the doctors performing the procedure used variable corneal incisions. As shown, a trend to undercorrection was found in all samples, which is related to the misalignment of the astigmatic correction [8]. Although predictability was better in our 
series than in the other studies compared, it should be considered that we only evaluated the results of a limited sample of cases with low to moderate astigmatism. Future studies are necessary to find whether these promising outcomes are also reproduced in larger samples of eyes including cases of higher astigmatism. Besides an excellent predictability, we also observed a significant improvement in CDVA (4 logMAR lines on average) in our case series, which confirmed the efficacy of IOL for the correction of the patient's aphakia and ametropia. This is consistent with previous studies evaluating the visual outcomes obtained with other types of toric IOLs [5-10]. The replacement of the optically degraded crystalline lens [12] with an IOL with an optimized optics plays the main role for this finding.

No significant changes were detected in keratometry and corneal astigmatism after surgery. In addition, no correlation between corneal and refractive astigmatic changes was detected, suggesting that the potential interference of the corneal incision with IOL astigmatic correction was minimal. Our results are consistent with previous studies, confirming that corneal astigmatism is not significantly modified with mini-incision cataract surgery and similar outcomes to those obtained with microincision surgery are achieved [13]. Indeed, it has been hypothesized that $2 \mathrm{~mm}$ may be the limit around which no optical changes would be induced by cataract surgery in the human cornea [13].

Ocular aberrometric outcomes were also evaluated by means of the Nidek OPD-Scan II system, which has been shown to be a useful tool for evaluating the visual quality after cataract surgery with IOL implantation. In the current study, aberrometric data were presented as a coefficient of the aberrations (A/B, total; H/B, higher order) present in an emmetropic eye of reference and compared to those corresponding to the measured eye in order to simplify the analysis. The ideal finding would have been values of 1 for the two coefficients analyzed (A/B and H/B), representing the equivalence with the emmetropic eye used as a reference. A significant increase in these coefficients was found after surgery, with values closer to 1 ( 0.65 and 0.82 for A/B and $\mathrm{H} / \mathrm{B}$, respectively). This last finding confirms the excellent visual quality provided by these implants. Indeed, no significant correlations were found between the aberrometric parameters evaluated and CDVA. In agreement with the aberrometric improvement observed, a significant increase of the Strehl ratio was observed postoperatively, confirming that an effective rehabilitation of the ocular optical system was induced.

Finally, IOL rotation was investigated in the current sample as well. A mean absolute value of IOL rotation of $3.33^{\circ}$ was found, ranging from 1 to $7^{\circ}$. This range is significantly lower than that reported with other types of toric IOL $[9,14]$. It should be considered that toric IOL rotations of less than $10^{\circ}$ generally induce changes in the eye's refraction of less than $0.50 \mathrm{D}$ [15]. Indeed, no significant correlations of the IOL rotation level with the postoperative magnitude of the cyl, $\mathrm{J}_{0}$ and $\mathrm{J}_{45}$ were found. Therefore, the IOL rotation level found in the current series is consistent with the excellent predictability of the astigmatic correction obtained. One potential factor accounting for this rotational stability may be the 3-point fixation haptics of the Tecnis ZCT, reducing the chances of rotation of the IOL in the postoperative period. However, more future research in this area is needed, using objective methods for assessing the IOL rotation level. It should be considered that variations in the features of the eye samples included in the different studies on toric IOLs might also account for the differences in the predictability of the astigmatic correction among the studies.

In conclusion, the Tecnis ZCT toric IOL is able to restore the distance visual function in eyes with cataract and low to moderate corneal astigmatism. This type of toric IOL is able to provide a highly predictable correction of the ocular astigmatism and a good postoperative ocular optical performance due to its minimal trend to rotation and its optimized optical properties. Future studies further evaluating the astigmatic vector changes for different 
Mazzini: Visual and Refractive Outcomes after Cataract Surgery with Implantation of a New Toric Intraocular Lens

levels of toricity and larger sample sizes are required to achieve a better understanding of the astigmatic corrective performance of this IOL type. An objective analysis of the behavior of this toric IOL within the capsular bag is also mandatory to better understand its potential as a corrective option for ocular astigmatism. Finally, long-term outcomes should also be reported to confirm the stability of the outcomes over time.

\section{Disclosure Statement}

The authors have no proprietary or commercial interest in the medical devices that are involved in this report.

\section{References}

1 Ramón ML, Piñero DP, Pérez-Cambrodí RJ: Correlation of visual performance with quality of life and intraocular aberrometric profile in patients implanted with rotationally asymmetric multifocal IOLs. J Refract Surg 2012;28:93-99.

-2 Alfonso JF, Puchades C, Fernández-Vega L, Montés-Micó R, Valcárcel B, Ferrer-Blasco T: Visual acuity comparison of 2 models of bifocal aspheric intraocular lenses. J Cataract Refract Surg 2009;35:672-676.

-3 Alió JL, ElKady B, Ortiz D, Bernabeu G: Clinical outcomes and intraocular optical quality of a diffractive multifocal intraocular lens with asymmetrical light distribution. J Cataract Refract Surg 2008;34:942-948.

4 Chang DF: Prospective functional and clinical comparison of bilateral ReZoom and ReSTOR intraocular lenses in patients 70 years or younger. J Cataract Refract Surg 2008;34:934-941.

-5 Mendicute J, Irigoyen C, Ruiz M, Illarramendi I, Ferrer-Blasco T, Montés-Micó R: Toric intraocular lens versus opposite clear corneal incisions to correct astigmatism in eyes having cataract surgery. J Cataract Refract Surg 2009;35:451-458.

-6 Ouchi M, Kinoshita S: AcrySof IQ toric IOL implantation combined with limbal relaxing incision during cataract surgery for eyes with astigmatism >2.50 D. J Refract Surg 2011;27:643-647.

7 Visser N, Nuijts RM, de Vries NE, Bauer NJ: Visual outcomes and patient satisfaction after cataract surgery with toric multifocal intraocular lens implantation. J Cataract Refract Surg 2011;37:2034-2042.

-8 Alió JL, Piñero DP, Tomás J, Alesón A: Vector analysis of astigmatic changes after cataract surgery with toric intraocular lens implantation. J Cataract Refract Surg 2011;37:1038-1049.

-9 Alió JL, Agdeppa MCC, Pongo VC, El Kady B: Microincision cataract surgery with toric intraocular lens implantation for correcting moderate and high astigmatism: pilot study. J Cataract Refract Surg 2010;36: 44-52.

10 Mendicute J, Irigoyen C, Aramberri J, Ondarra A, Montés-Micó R: Foldable toric intraocular lens for astigmatism correction in cataract patients. J Cataract Refract Surg 2008;34:601-607.

11 Thibos LN, Horner D: Power vector analysis of the optical outcomes of refractive surgery. J Cataract Refract Surg 2001;27:80-85.

12 Alió JL, Schimchak P, Negri HP, Montés-Micó R: Crystalline lens optical dysfunction through aging. Ophthalmology 2005;112:2022-2029.

13 Alió JL, Elkady B, Ortiz D: Corneal optical quality following sub $1.8 \mathrm{~mm}$ micro-incision cataract surgery versus $2.2 \mathrm{~mm}$ mini-incision coaxial phacoemulsification. Middle East Afr J Ophthalmol 2010;17:94-99.

-14 Holland E, Lane S, Horn JD, Ernest P, Arleo R, Miller KM: The AcrySof toric intraocular lens in subjects with cataracts and corneal astigmatism: a randomized, subject-masked, parallel-group, 1-year study. Ophthalmology 2010;117:2104-2111.

15 Felipe A, Artigas JM, Díez-Ajenjo A, García-Domene C, Alcocer P: Residual astigmatism produced by toric intraocular lens rotation. J Cataract Refract Surg 2011;37:1895-1901.

16 Ahmed II, Rocha G, Slomovic AR, Climenhaga H, Gohill J, Grégoire A, Ma J; Canadian Toric Study Group: Visual function and patient experience after bilateral implantation of toric intraocular lenses. J Cataract Refract Surg 2010;36:609-616.

-17 Hoffmann PC, Auel S, Hütz WW: Results of higher power toric intraocular lens implantation. J Cataract Refract Surg 2011;37:1411-1418. 
Table 1. Summary of the visual, refractive and keratometric outcomes in the current series during the follow-up

\begin{tabular}{|c|c|c|c|}
\hline & Preoperative values & $\begin{array}{l}\text { Postoperative values at } \\
6 \text { months }\end{array}$ & $\mathrm{p}$ value \\
\hline logMAR UDVA & - & $\begin{array}{l}0.02(0.06) \\
0.00(0.00-0.22)\end{array}$ & - \\
\hline Manifest sphere (D) & $\begin{array}{l}-0.07(2.47) \\
0.00(-4.50 \text { to } 3.00)\end{array}$ & $\begin{array}{l}0.01(0.06) \\
0.00(0.00-0.25)\end{array}$ & 0.80 \\
\hline Manifest cylinder (D) & $\begin{array}{l}-1.50(0.98) \\
-1.25(-3.50 \text { to } 0.00)\end{array}$ & $\begin{array}{l}-0.32(0.25) \\
-0.50(-0.75 \text { to } 0.00)\end{array}$ & $<0.01$ \\
\hline $\mathrm{J}_{0}(\mathrm{D})$ & $\begin{array}{l}-0.34(0.69) \\
-0.31(-1.34 \text { to } 1.00)\end{array}$ & $\begin{array}{l}-0.10(0.13) \\
-0.08(-0.37 \text { to } 0.13)\end{array}$ & 0.16 \\
\hline $\mathrm{J}_{45}$ (D) & $\begin{array}{l}0.02(0.48) \\
0.00(-1.12 \text { to } 1.23)\end{array}$ & $\begin{array}{l}0.03(0.11) \\
0.00(-0.22 \text { to } 0.25)\end{array}$ & 0.85 \\
\hline $\mathrm{B}(\mathrm{D})$ & $\begin{array}{l}2.23(0.97) \\
2.15(0.71-4.50)\end{array}$ & $\begin{array}{l}0.22(0.17) \\
0.25(0.00-0.53)\end{array}$ & $<0.01$ \\
\hline$M(D)$ & $\begin{array}{l}-0.82(2.16) \\
-1.00(-4.50 \text { to } 2.50)\end{array}$ & $\begin{array}{l}-0.01(0.13) \\
0.00(-0.50 \text { to } 0.25)\end{array}$ & 0.15 \\
\hline logMAR CDVA & $\begin{array}{l}0.41(0.23) \\
0.40(0.15-1.00)\end{array}$ & $\begin{array}{l}0.02(0.05) \\
0.00(0.00-0.22)\end{array}$ & $<0.01$ \\
\hline $\mathrm{K} 1$ (D) & $\begin{array}{l}43.55(1.79) \\
43.60(40.50-47.00)\end{array}$ & $\begin{array}{l}43.58(1.74) \\
43.40(40.80-46.90)\end{array}$ & 0.52 \\
\hline $\mathrm{K} 2$ (D) & $\begin{array}{l}45.21(1.71) \\
45.40(42.30-48.80)\end{array}$ & $\begin{array}{l}45.22(1.70) \\
45.40(42.70-48.70)\end{array}$ & 0.77 \\
\hline
\end{tabular}

Values are presented as mean (SD) and median (range).

$\mathrm{B}=$ Overall blurring strength of the manifest spherocylindrical error; $\mathrm{K} 1$ = mean keratometry in the flattest meridian in the 3-mm central zone; $\mathrm{K} 2$ = mean keratometry in the steepest meridian in the 3-mm central zone. 
Mazzini: Visual and Refractive Outcomes after Cataract Surgery with Implantation of a

New Toric Intraocular Lens

Table 2. Summary of the ocular aberrometric outcomes in the current series during the follow-up

\begin{tabular}{llll}
\hline & Preoperative values & $\begin{array}{l}\text { Postoperative values at } \\
6 \text { months }\end{array}$ & p value \\
\hline A/B coefficient & $0.31(0.17)$ & $0.60(0.16)$ & $<0.01$ \\
& $0.31(0.13-0.68)$ & $0.59(0.35-0.85)$ & 0.02 \\
\hline H/B coefficient & $0.65(0.19)$ & $0.82(0.20)$ & $<0.01$ \\
\hline Strehl ratio & $0.62(0.31-1.10)$ & $0.83(0.54-1.14)$ & \\
& $0.02(0.03)$ & $0.08(0.04)$ & $0.07(0.01-0.15)$ \\
\end{tabular}

Values are mean (SD) and median (range).

Table 3. Summary of the clinical outcomes obtained by different authors with other modalities of toric IOLs

\begin{tabular}{|c|c|c|c|c|c|c|c|c|}
\hline Author (year) & $\begin{array}{l}\text { Eyes } \\
\mathrm{n}\end{array}$ & IOL type & $\begin{array}{l}\text { Mean logMAR } \\
\text { UDVA (SD) }\end{array}$ & $\begin{array}{l}\text { M } \\
\text { within } \\
\pm 0.50 \mathrm{D}\end{array}$ & $\begin{array}{l}\mathrm{J}_{0} \text { and } \mathrm{J}_{45} \\
\text { within } \\
\pm 0.50 \mathrm{D}\end{array}$ & $\begin{array}{l}\text { Mean } \\
\text { preop cyl } \\
\text { SD }\end{array}$ & $\begin{array}{l}\text { Mean } \\
\text { postop cyl } \\
\text { SD }\end{array}$ & $\begin{array}{l}\text { Follow- } \\
\text { up } \\
\text { months }\end{array}$ \\
\hline Mendicute et al. (2008) [10] & 30 & AcrySof & $0.16(0.18)$ & $90 \%$ & $\begin{array}{r}80 \% \\
93.9 \%\end{array}$ & $-2.34(1.28)$ & $-0.72(0.43)$ & 3 \\
\hline Mendicute et al. (2009) [5] & 40 & AcrySof & $0.11(0.15)$ & $90 \%$ & $\begin{array}{c}95 \% \\
100 \%\end{array}$ & $-1.75(0.71)$ & $-0.62(0.46)$ & 3 \\
\hline Ahmed et al. (2010) [16] & 234 & AcrySof & $\begin{array}{l}0.05(0.11) \\
\text { (binocular) }\end{array}$ & $77.2 \%$ & - & $-1.70(0.40)$ & $-0.40(0.40)$ & 6 \\
\hline Alió et al. (2010) [9] & 21 & Acri.Comfort 646TLC & $0.65(0.22)$ (decimal) & - & - & $-4.46(2.23)$ & $-0.45(0.63)$ & 3 \\
\hline $\begin{array}{l}\text { Ouchi and Kinoshita (2011) } \\
\text { [6] }\end{array}$ & 22 & AcrySof IQ & $0.13(0.19)$ & - & - & $-3.90(1.69)$ & $-0.94(0.57)$ & 6 \\
\hline Alió et al. (2011) [8] & 27 & AcrySof & $0.16(0.15)$ & - & - & $-2.87(0.78)$ & $-0.94(0.40)$ & 6 \\
\hline Hoffmann et al. (2011) [17] & 40 & AcrySof & $0.20(0.11)$ & - & - & $-3.49(1.31)$ & $-0.67(0.32)$ & 3 \\
\hline Current study (2012) & 19 & Tecnis ZCT & $0.02(0.06)$ & $100 \%$ & $\begin{array}{l}100 \% \\
100 \%\end{array}$ & $-1.50(0.98)$ & $-0.32(0.25)$ & 6 \\
\hline
\end{tabular}




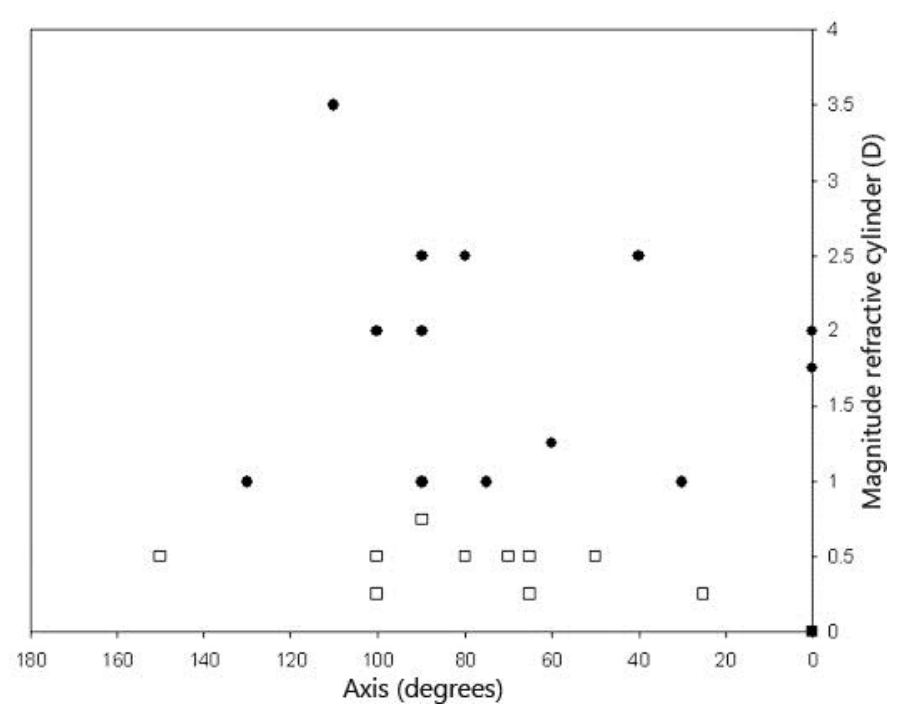

Fig. 1. Vector display showing a comparison of the preoperative (filled circles) and postoperative (empty squares) cyl.

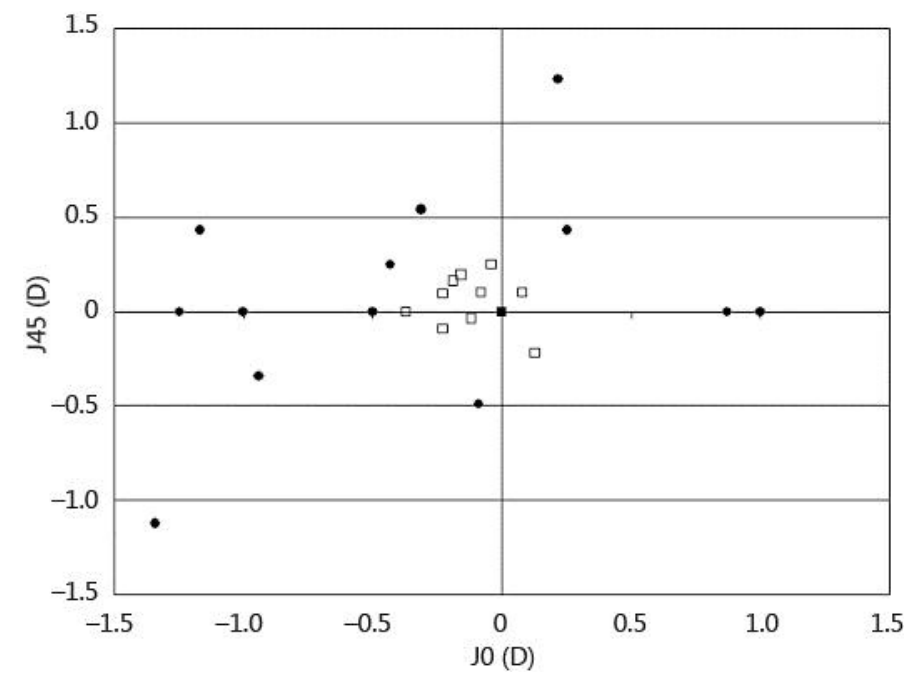

Fig. 2. Scattergram showing the relationship between the preoperative (filled circles) and postoperative (empty squares) power vector components $\mathrm{J}_{0}$ and $\mathrm{J}_{45}$ of the cyl. 